TP Periodica Polytechnica Mechanical Engineering

\author{
58(2), pp. 113-117, 2014 \\ DOI:10.3311/PPme.7275 \\ Creative Commons Attribution (1)
}

RESEARCH ARTICLE

\section{Tensile behavior of multiple forged 6082 Al alloy}

Tareg S. Ben Naser, Kristóf Bobor, György Krállics

RECEIVED 17 January 2014; ACCEPTED AFter REVISION 18 ApRIL 2014

\section{Abstract}

The present study focus on the influence of multiple forging $(M F)$ on the tensile behavior of 6082 aluminium alloy, where the MF specimens were achieved using multi-step closed die forging. Cylindrical tensile specimens were machined from the MF specimens then subjected to tensile testing. Beside the main target of the study, the effect of MF on microstructure homogeneity and the fracture surface of the samples were studied using hardness testing, optical and scanning electron microscopy respectively.

The results show the influence of MF on the tensile strength and the maximum elongation; with increasing passes of MF the strength increases while the maximum elongation decreases. The hardness measurement results demonstrate the structure homogeneity, the fractography pictures show ductile fracture of the specimen, and the micrographs describe the microstructure development during $M F$ process.

\section{Keywords}

Multiple forging $\cdot$ tensile behavior $\cdot$ aluminium alloy

\section{Tareg S. Ben Naser}

Department of Materials Science and Engineering, Faculty of Mechanical Engineering,

Budapest University of Technology and Economics, Bertalan Lajos út 7., H-1111 Budapest, Hungary

e-mail: taregnaser@yahoo.com

\section{Kristóf Bobor}

Department of Materials Science and Engineering, Faculty of Mechanical Engineering,

Budapest University of Technology and Economics, Bertalan Lajos út 7., H-1111 Budapest, Hungary e-mail: bobor@eik.bme.hu

\section{György Krállics}

Department of Materials Science and Engineering, Faculty of Mechanical Engineering,

Budapest University of Technology and Economics,

Bertalan Lajos út 7., H-1111 Budapest, Hungary

email: krallics@eik.bme.hu

\section{Introduction}

The 6xxx aluminum alloys have moderate to high strength and very good corrosion resistance. Because of this properties it is suitable for wide range of applications including structure elements of buildings, marine application, machine parts and other applications [1]. Because of these advantageous characteristics several methods were established to improve the mechanical properties. Ones of them are the so-called sever plastic deformation (SPD) techniques [2, 3, 4, 5], where the material undergoes high extent of plastic deformation that leads to grain refinement, up to $100 \sim 1000 \mathrm{~nm}$ average size and improve several physical and mechanical properties [6, 7].

MF is a SPD method of formation nano or ultra-fine grained bulk billets where the materials undergo several passes of forging with change of deformation axes $[3,8]$. The possibility of the production of large-size specimens is the biggest advantage of the method compared with other SPD techniques; however it has less structure homogeneity [3]. Formerly Valiev et. al. [3] and Ringeval et al. [9, 8] used free forging operations or open die forging respectively to perform the MF process. In this work closed die was used; Figure 1 shows the principles for first and second pass which can be repeat as it is desired. The main reason for the choice of closed die forging that the specimen's shape remains nearly unchanged even after several passes of deformation because of the constrained deformation. On the other hand comparing the upsetting to the same height reduction in open and closed dies, in case of the letter one the deformation is higher. In this case the material is constrained to fill the tool cavities, which gives rise to plastic deformation, while by open die forging the material flow is much less constrained.

The strength and ductility of materials were investigated by tensile test as a widely used inspection method [10] The tensile tests show that the material after SPD have increased strength and decreased but still significant ductility [11, 12, 13, 14, 15]. The hardness as another strength related mechanical property can be used to characterize the homogeneity of the microstructure [12]. 
The aim of our work was to investigate the tensile behavior and the material structure development during multi-step MF of 6082 aluminium alloy. Tensile tests were carried and the hardness distribution in the samples' cross section were investigated before the forging and after each deformation steps. The fractured surface of the material were studied by scanning electron microscopy.

\section{Material and the experiments}

Material Table 1 shows the chemical composition of the tested 6082 aluminium alloy. The initial material was received as hard extruded rod $20 \mathrm{~mm}$ in diameter and was cut to $100 \mathrm{~mm}$ long specimens.

Multiple forging (MF) The principle of our method is to subject the workpiece $(\varnothing 20 \times 100 \mathrm{~mm})$ to several cold forging passes while between the passes it is rotated by 90 degrees along its longitudinal axes. The die's shape constrains the deformation of the materials in every directions: there is no significant longitudinal deformation and the cross sections geometry after each pass is approximately the same (24.1 X $13.25 \mathrm{~mm})$. The steps were repeated five times. Figure 1 shows the schematic figure of the dies and the principle of the process which was applied during experiments.

Tensile and hardness test. The samples for tensile test were prepared in the longitudinal direction of the workpiece. The tensile tests were performed by an MTS 810 universal mechanical testing machine with constant cross head velocity $(5 \mathrm{~mm} / \mathrm{s})$ at room temperature. Figure 2 shows the tensile specimens' dimensions.

Vickers hardness was measured using $5 \mathrm{~kg}$ (HV5) main load to investigate the hardness distribution in the cross section. For these measurements the specimen were cut, and the surface was grinded and polished. Each cross section was tested in 7 spots (see Figure 5) with minimum 10 measurements in each one.

Fractography and microscopy. After the tensile testing the fractured surface of samples from the initial material and from every step were investigated. In order to analyze the fracture behavior scanning electron microscopic (SEM) images were made in the characteristic points of the tensile fracture surfaces. For the optical microscopy the specimens were cut, grinded, polished, and chemical etched with Keller's reagent to reveal the grain boundaries.

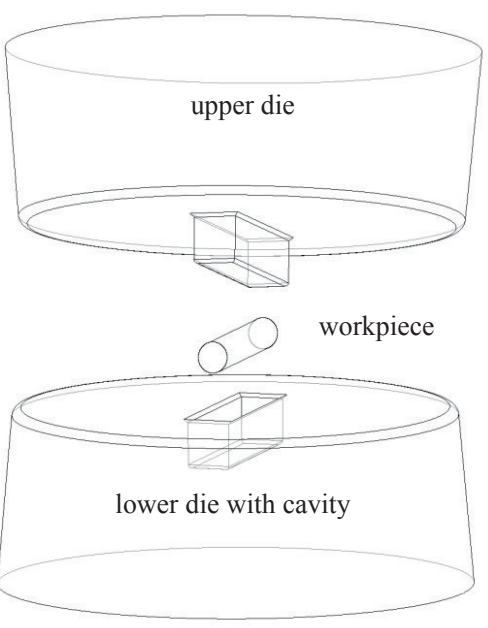

The schematic 3D view of the tools and the workpiece

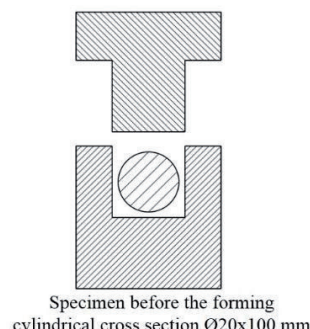

cylindrical cross sectio

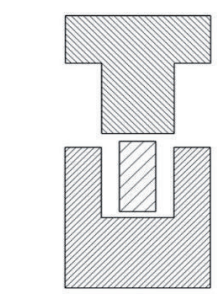

Rotation of the specimen by $90^{\circ}$

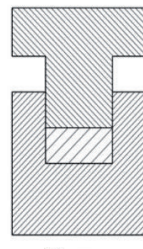

First pass

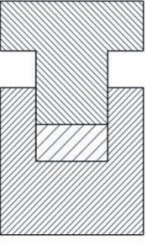

Second pass

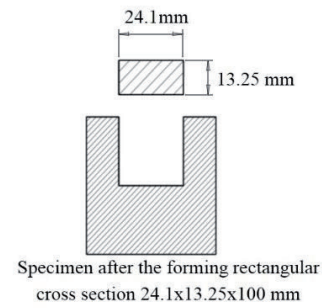

Further forming steps

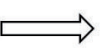

Fig. 1. The schematic 3D view of the tools and the workpiece and the principle of multiple forging using closed dies.

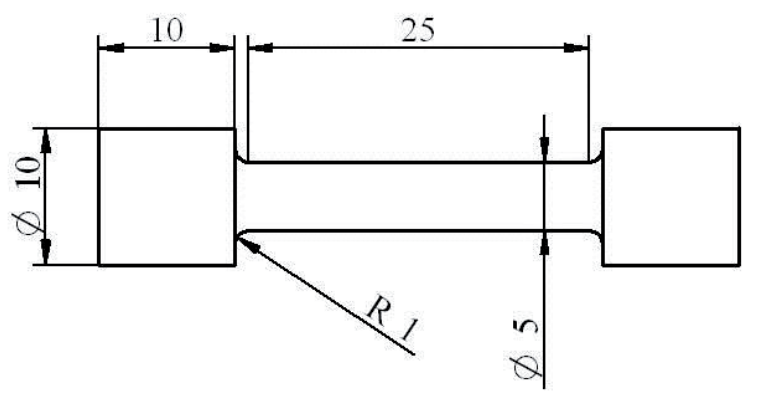

Fig. 2. Tensile specimens' dimensions (all dimensions are in $\mathrm{mm}$ )

Tab. 1. Chemical composition of the 6082 aluminium alloy (according to EN AW-6082)

\begin{tabular}{ccccccccccc}
\hline Material & $\mathrm{Mg}$ & $\mathrm{Si}$ & $\mathrm{Mn}$ & $\mathrm{Fe}$ & $\mathrm{Ti}$ & $\mathrm{Cu}$ & $\mathrm{Zn}$ & other each & other total & Al \\
\hline & 0.6 & 0.7 & 0.40 & $\max$ & $\max$ & $\max$ & $\max$ & $\max$ & $\max$ & balance \\
WT\% & - & - & - & 0.5 & 0.10 & 0.1 & 0.2 & 0.05 & 0.15 & \\
\hline
\end{tabular}


Finite element simulation. The MF process was analyzed using finite element (FEM) method. By the calculations the updated Lagrangian method and the von Mises yield criteria was used with a rigid-hardening plastic material model. 4-node isoparametric tetrahedral elements were used with global remeshing. The dies were considered as rigid bodies, and the temperature were kept constant. The simulations were performed using Simufact Forming software.

\section{Results and discussions Tensile test}

Figure 3 shows the engineering stress - strain curve for initial material and all MF-ed specimens. The evaluated results of the test, the tensile strength $R_{m}$, yield strength $R_{p 0.2}$ as well as the maximum elongation Eu, are shown in the Figure 4. This two figures display the effect of MF on the material. The initial material has lowest strength and highest elongation. The yield strength increases and the elongation decreases notably after first pass, then a small interval fluctuation can be observed in the following passes. We can state that the tested mechanical properties don't change remarkably after the $2^{\text {nd }}$ pass: the strength and the ductility are varying about constant values. The tensile strength should have increasing tendency as the total strain increases, which cannot be seen in our results. An explanation of this deviation can be that recrystallization or recovery was taking place during the $3^{\text {rd }}$ and $5^{\text {th }}$ passes.

\section{Hardness measurements}

The hardness results of the MF steps show similar tendency to that of tensile results. There are quite considerable rise in hardness after the first pass, then it has slightly change.

The specimens' cross sections were divided to seven areas and minimum 10 measurements were taken in each one as it is shown on Figure 5. The results of the hardness test measurements were compared with the distribution of the equivalent plastic strain calculated by FEM as illustrated on Figure 5. It is clearly shown that the distribution of plastic strain and HV5 are similar in the cross section.

$a$

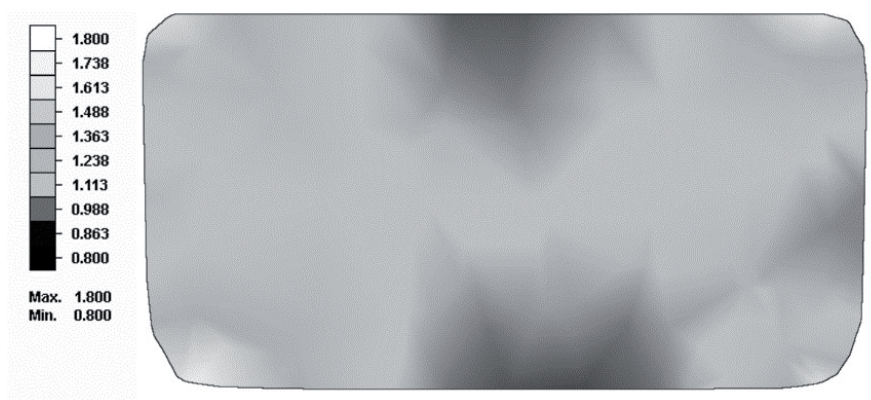

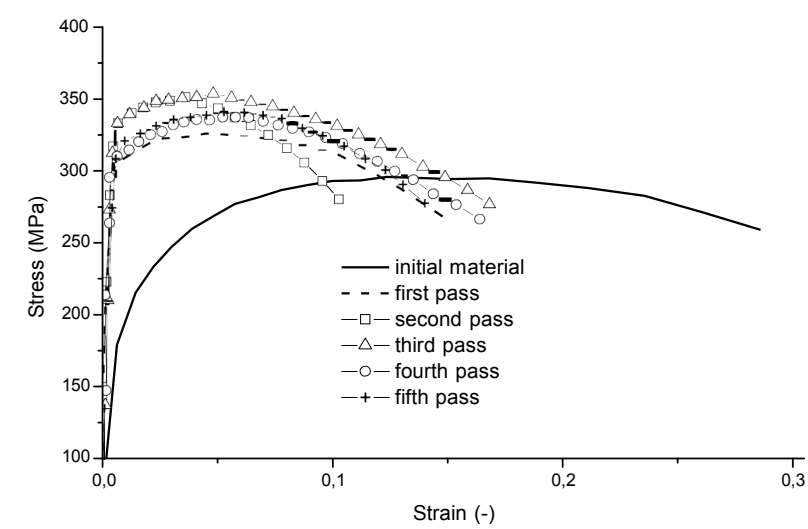

Fig. 3. Engineering stress - strain curve for initial and MF passes

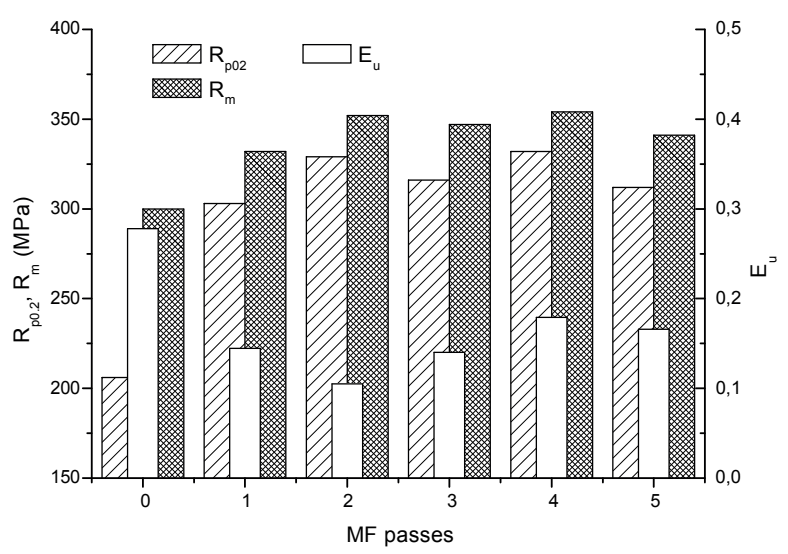

Fig. 4. Tensile strength $\left(\mathrm{R}_{\mathrm{p} 0.2}\right)$, yield stress $\left(\mathrm{R}_{\mathrm{m}}\right)$ and maximum elongation $\left(\mathrm{E}_{\mathrm{u}}\right)$ after multiple forging.

Figure 6 displays the mean hardness values over the passes. The error bars show the standard deviation value. The mean values show the overall change on the hardness, which is in correspondence with the tensile test results - there is not significant hardening after the second pass. The standard deviation indicates the homogeneity of the microstructure in the cross section. According to this latter it can be said that the second and third pass have the maximum structure homogeneity comparing to the other MF passes.

$b$

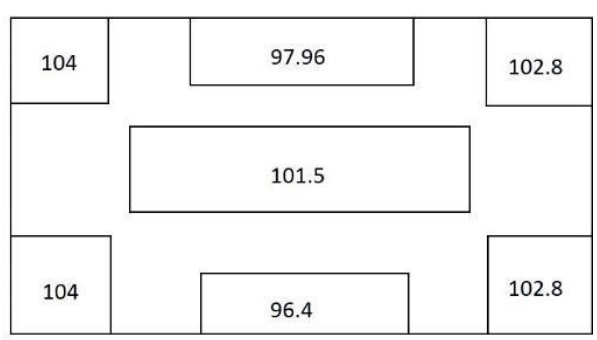

Fig. 5. a) The equivalent plastic strain distribution in the specimen's cross section and b) the mean value of HV5 hardness test measurements after the $2^{\text {nd }}$ pass. 


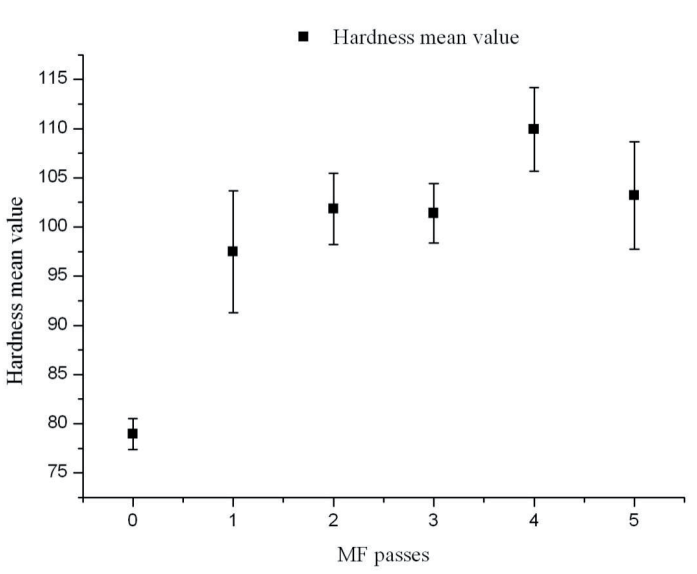

Fig. 6. Fig. 6

\section{Fractography and microstructure pictures}

Figure 7 shows the fractured surfaces after the tensile test. It can be stated that no significant difference can be found between the samples and in every case the material's behavior was rather ductile than brittle.

The refinement of crystallites can be observed by optical microscopy. Figure 8. shows the microstructure of the initial state and after four passes of deformation in characteristic regions of the cross section. It can be stated that initially grains have approximately equiaxed shape with a size of $20 \mu \mathrm{m}$ in average. During the deformation the grain size decreases and after four passes there are strongly elongated grains with significantly finer grain size that the original one.

\section{Summary}

In the present study the $\mathrm{Al} 6082$ alloy was multiple forged in closed dies up to 5 passes. The mechanical properties, microstructure homogeneity, as well as fractured surface of the tensile specimens of the initial and the deformed material were investigated. The results can be summarized as follows:

1) The yield strength increases notably after first pass and after the second pass the mechanical properties don't change remarkably.

2) By the samples forged 3-5 times a small interval fluctuation of the mechanical properties can be observed. A possible explanation of it can be the recrystallization or recovery during the forging.

3) The hardness measurement show the same trend as tensile testing: there is not significant hardening after the second pass.

4) In correspondence with the finite element calculations the hardness measurements show that the deformation is not homogeneous in the cross section. The second and third passes have the maximum structure homogeneity comparing to the other MF passes.

5) The fractography indicated that material's behavior was rather ductile than brittle even after five passes of deformation.

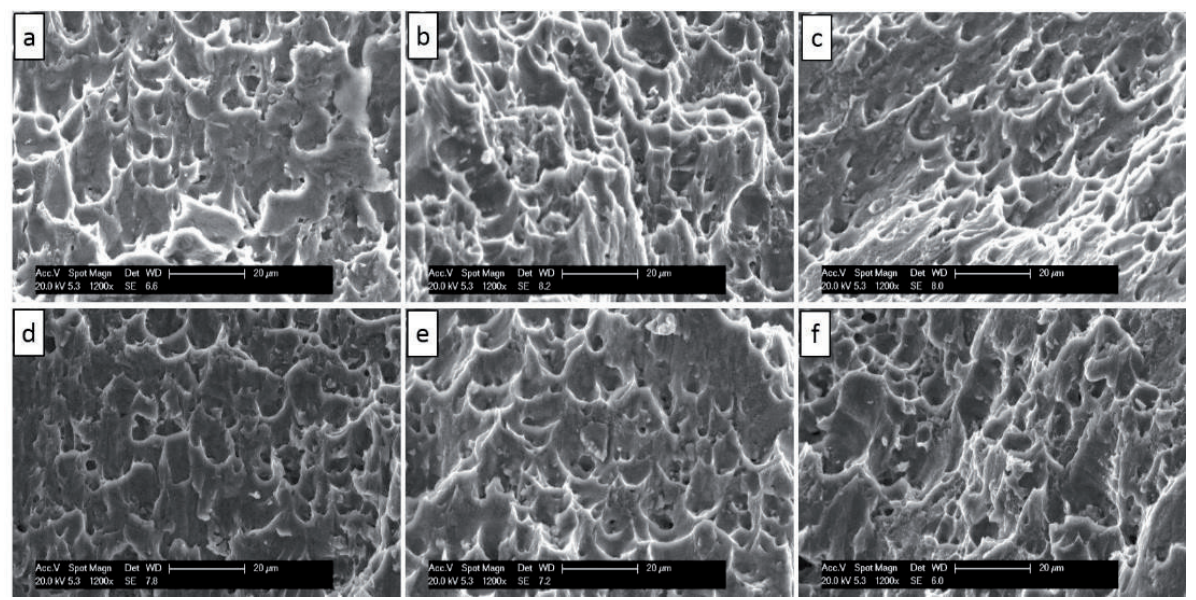

Fig. 7. SEM images of the fractured surfaces after the tensile test. a) initial material, b-f) MF specimens ( b) - after first, f) - after the fifth step)
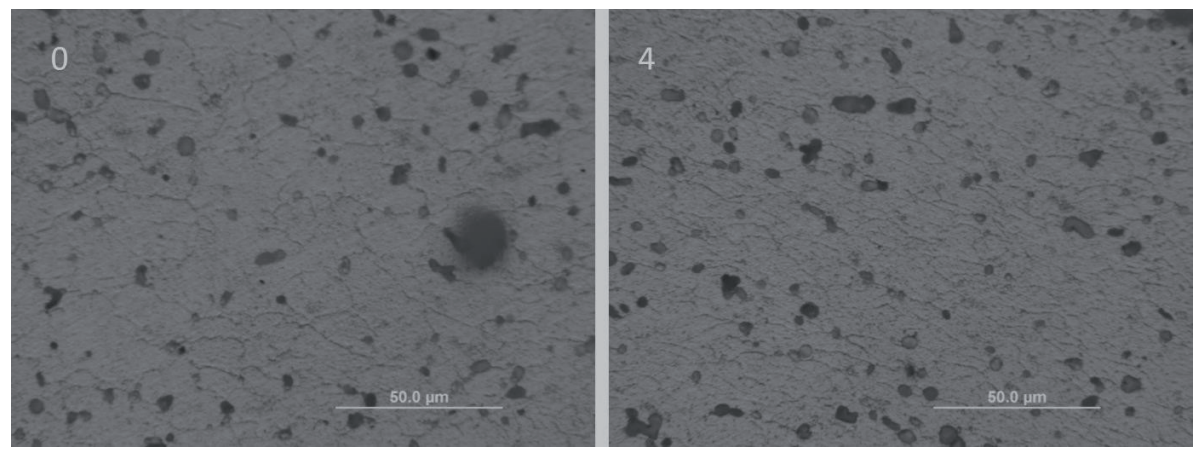

Fig. 8. Microstructure development during MF using optical microscopy; microstructure of the initial material and after the forth pass. 


\section{References}

1 Metals handbook, Vol. 2., Properties and selection: nonferrous alloys and special- purpose metals, ASM, (1979).

2 Zherebtsov S. V., Salishchev G. A., Galeyev R. M., Valiakhmetov O. R., Mironov S. Yu., Semiatin S. L., Production of submicrocrystalline structure in large-scale Ti-6Al-4V billet by warm severe deformation processing. Scripta Materialia, 51 (12), pp. 1147-1151, (2004).

DOI: $10.1016 /$ j.scriptamat.2004.08.018

3 Valiev R. Z., Islamgaliev R. K., Alexandrov I. V., Bulk nanostructured materials from severe plastic deformation. Progress in Materials Science, 45 (2), pp. 103-189, (2000). DOI: $10.1016 / \mathrm{S} 0079-6425(99) 00007-9$

4 Han B. Q., Mohamed F. A., Lavernia E. J., Tensile behavior of bulk nanostructured and ultrafine grained aluminum alloys. Journal of Materials Science, 38 (15), pp. 3319-3324, (2003). DOI: $10.1023 / \mathrm{A}: 1025150407956$

5 Chang S. Y., Lee J. G., Park K. T., Shin D. H., Microstructures and Mechanical Properties of Equal Channel Angular Pressed 5083 Al Alloy. Materials Transactions, 42 (6), pp. 1074-1080, (2001).

6 Salishchev G. A., Galeev R. M., Malysheva S. P., Zherebtsov S. V., Mironov S. Yu., Valiakhmetov O. R., Ivanisenko É. I., Formation of submicrocrystalline structure in titanium and titanium alloys and their mechanical properties. Metal Science and Heat Treatment, 48 (1-2), pp. 63-69, (2006).

DOI: $10.1007 / \mathrm{s} 11041-006-0045-7$

7 Mulyukov R. R., Imayev R. M., Nazarov A. A., Production, properties and application prospects of bulk nanostructured materials. Journal of Materials Science, 43 (23-24), pp. 7257-7263, (2008). DOI: $\underline{10.1007 / \mathrm{s} 10853-008-2777-9}$
8 Sakai T., Miura H., Yang X., Ultrafine grain formation in face centered cubic metals during severe plastic deformation. Materials Science and Engineering A, 499 (1-2), pp. 2-6, (2009). DOI: $\underline{10.1016 / \text { j.msea.2007.11.098 }}$

9 Ringeval S., Driver J. H., Multiple Forging Textures and Microstructures in Al Alloys. Materials Science Forum, 550, pp. 181-192, (2007).

10 Metals handbook, Vol. 8., Mechanical Testing, ASM, (1985).

11 Padap K., Chaudhari G. P., Pancholi V., Nath S. K., Warm multiaxial forging of AISI 1016 steel. Materials and Design, 31 (8), pp. 3816-3824, (2010). DOI: $10.1016 /$ i.matdes.2010.03.030

12 Naser T. S. B., Krállics Gy., The effect of multiple forging and cold rolling on bending and tensile behavior of Al 7075 alloy. Materials Science Forum, 729, pp. 464-469 (2013).

13 Valiev R. Z., Strength and Ductility of Nanostructure SPD Metals. Metallic Materials with High Structural Efficiency, 146, pp. 79-90, (2004).

DOI: $10.1007 / 1-4020-2112-7 \_7$

14 Valiev R., Murashkin Yu. M., Straumal B. B., Enhanced Ductility in Ultrafine-Grained Al Alloys Produced by SPD Techniques. Materials Science Forum, Vol. 633-634, pp. 321-332, (2009).

15 Beygelzimer Y., Prokof'eva O., Kulagin R., Varyukhin V., Synkov S., Measures of Ductility for UFG Materials Obtained by SPD. Materials Science Forum, Vol. 633-634, pp. 223-230, (2009). 